\title{
A Retrospective Radiographic Study of Coronal-Periapical Status and Root Canal Filling Quality in a Selected Adult Turkish Population
}

\author{
B. Ureyen Kaya ${ }^{a}$ A.D. Kececi ${ }^{a}$ H.E. Guldas ${ }^{a}$ H. Orhan ${ }^{b}$ \\ ${ }^{a}$ Department of Endodontics, Faculty of Dentistry, and b Department of Biostatistics, Faculty of Medicine, \\ Süleyman Demirel University, Isparta, Turkey
}

\section{Key Words}

Coronal status · Digital panoramic radiography · Periapical index Periapical status $\cdot$ Root canal filling quality

\begin{abstract}
Objective: To investigate the oral health (with regard to the periapical status, quality of root fillings and coronal restorations) in an urban adult Turkish subpopulation using digital panoramic radiographs. Materials and Methods: One thousand digital panoramic radiographs involving 28,000 teeth were selected from the archive of the Public Oral and Dental Health Center of Isparta. Coronal status (the type of restoration, signs of marginal leakage or decay), root filling quality (length and lateral seal) and periapical status (according to Periapical Index, PAI) were evaluated. Correlations between apical periodontitis (AP) and the quality of root fillings or coronal restorations were statistically analyzed using the $x^{2}$ test. Results: Of the 28,000 teeth evaluated, 22,380 (80.0\%) were sound, 4,732 (16.9\%) were missing, 753 (2.6\%) were filled and $135(0.5 \%)$ were decayed. Of the 753 coronal restorations, $400(53.1 \%)$ were radiographically acceptable. Of the 23,268 teeth, 601 (2.6\%) were root filled and 247 root fillings were adequate. Ninety-five (15.8\%) root-filled teeth had AP (PAI 3-5). Out of the total, the AP prevalence was $0.4 \%$ in root-filled teeth and $0.8 \%$ in teeth without root fillings. The
\end{abstract}

presence of AP was significantly correlated with inadequate coronal restorations and root canal fillings $(p=0.000)$. Conclusion: Tooth type, quality and type of coronal restorations, and length and homogeneity of root fillings significantly affected periapical status.

Copyright $\odot 2013$ S. Karger AG, Basel

\section{Introduction}

Increasing success rate in root canal therapy has been reported [1], which may have a significant contribution to the improvement of oral health in recent years. The outcome of root canal treatment is positively correlated with the technical quality of the root filling [2]. However, it has been suggested that the primary contributing factor to the presence or development of periapical lesions is not only the filling of the root canal but also the sealing of the coronal restoration [3].

The assessment of the periapical status in different populations is important because it may help to define the treatment needs of the population and evaluate the effects of various endodontic interventions on treatment outcomes [4]. Cross-sectional [5-9] and epidemiological [3, 10] studies using different methods and criteria have documented the prevalence of apical periodontitis (AP) in

\begin{tabular}{ll}
\hline KARGER & $\begin{array}{l}\text { ○ 2013 S. Karger AG, Basel } \\
1011-7571 / 13 / 0224-0334 \$ 38.00 / 0 \quad \text { Karger }\end{array}$ \\
E-Mail karger@karger.com & $\begin{array}{l}\text { This is an Open Access article licensed under the terms of the } \\
\text { www.karger.com/mpp }\end{array}$ \\
$\begin{array}{l}\text { Creative Commons Attribution-NonCommercial 3.0 Un- } \\
\text { ported license (CC BY-NC) (www.karger.com/OA-license), } \\
\text { applicable to the online version of the article only. Distribu- } \\
\text { tion permitted for non-commercial purposes only. }\end{array}$
\end{tabular}

Assist. Prof. Dr. Bulem Ureyen Kaya

Süleyman Demirel Üniversitesi, Diş Hekimliği Fakültesi Endodonti AD

TR-32260 Kampüs-Isparta (Turkey)

E-Mail bureyen@ hotmail.com 
Table 1. Radiographic evaluation parameters and scores used in the present study

\begin{tabular}{ll}
\hline Parameters & Score \\
\hline Radiographic coronal status [6] & $\begin{array}{l}\text { Intact restoration without signs of leakage (acceptable) } \\
\text { Restoration with open margin (unacceptable) } \\
\text { Restoration with recurrent decay (unacceptable) }\end{array}$ \\
\hline Length of root filling [6] & $\begin{array}{l}\text { Root filling terminating } 0 \text { to } \leq 2 \mathrm{~mm} \text { from the radiographic apex (acceptable) } \\
\text { Root filling terminating }>2 \mathrm{~mm} \text { from the radiographic apex (unacceptable) } \\
\text { Root filling extending beyond the radiographic apex (unacceptable) }\end{array}$ \\
\hline Lateral seal of root filling [3] & $\begin{array}{l}\text { Adequate in the coronal } 1 / 2 \text { of the root filling }+ \text { adequate in the apical } 1 / 2 \text { of the root filling } \\
\text { Adequate in the coronal } 1 / 2 \text { of the root filling }+ \text { inadequate in the apical } 1 / 2 \text { of the root filling }\end{array}$ \\
& $\begin{array}{l}\text { Inadequate in the coronal } 1 / 2 \text { of the root filling }+ \text { adequate in the apical } 1 / 2 \text { of the root filling } \\
\text { Inadequate in the coronal } 1 / 2 \text { of the root filling }+ \text { inadequate in the apical } 1 / 2 \text { of the root filling }\end{array}$ \\
\hline PAI [11] & $\begin{array}{l}\text { Normal periapical structures } \\
\text { Small changes in bone structure } \\
\text { Changes in bone structure with some mineral loss } \\
\text { Periodontitis with well-defined radiolucent area } \\
\text { Severe periodontitis with exacerbating features }\end{array}$ \\
&
\end{tabular}

various countries. In recent years, the Periapical Index (PAI) developed by Ørstavik [11] has been the most accepted method to determine the periapical status in epidemiological studies $[3,5]$ and clinical trials $[12,13]$. The aim of this study was to investigate the oral health (with regard to the periapical status, quality of root fillings and coronal restorations) in an urban adult Turkish subpopulation using digital panoramic radiographs.

\section{Materials and Methods}

Digital panoramic radiographs of patients $(n=3,850)$ first attending the Public Oral and Dental Health Center in Isparta, Turkey, taken between January and June 2011, were selected from the archive of this center. The Public Oral and Dental Health Center renders a primary dental health care service especially to patients with government health insurance. The complicated cases are referred to the dental faculty in Isparta and some private specialists. Digital panoramic radiographs are taken for most of the adult attendees and the treatments are performed by general dentists. This center has a huge capacity with approximately 700 attendees daily covering $85 \%$ of rural and $60 \%$ of urban areas of the population.

Odd-numbered digital panoramic radiographs were examined according to exclusion criteria and the number of the sample reduced to 1,000 for this retrospective cross-sectional study. The digital panoramic radiographs obtained from patients younger than 18 years with poor image quality, particularly in the upper and lower anterior regions, those obtained from patients having $\leq 9$ remaining teeth, or those obtained from patients who were not regular residents of Isparta were excluded.

\section{Observer Agreement for Radiographic Evaluation}

All radiographs were taken by the same operator using a panoramic digital radiography device (Orthophos XG 5; Sirona, Tex., USA). Digital images were examined using Photoshop 6.0 Software (Adobe Systems Inc., San Jose, Calif., USA) at a ratio of 1:1. Three observers, 2 endodontists with clinical experience of 20 (A.D.K.) and 11 (B.U.K.) years and a postgraduate student (H.E.G.) with 3 years of clinical experience, evaluated the radiographs. Before the evaluation, the observers participated in calibration training, which consisted of 50 randomly selected panoramic radiographs. The strength of interobserver agreement was determined by calculation of kappa value (kappa $=0.87)$ [14]. In case of disagreements and difficult borderline cases a consensus decision was reached by negotiating these cases and a 'joint evaluation' (JE) was established. Intra-examiner reproducibility was evaluated by repeated scoring of the same 50 radiographs at 2 months after the first examination. The intra-observer agreement on PAI scores for the 3 observers (A.D.K., B.U.K. and H.E.G.) produced kappa values of $0.91,0.88$ and 0.84 , respectively.

\section{Radiographic Evaluation}

All teeth, except third molars, were recorded using the Federation Dentaire Internationale nomenclature from the panoramic radiographs. The teeth were evaluated radiographically and recorded as decayed, missing, filled, coronal restoration or root filling, and the periapical status were scored according to the criteria listed in table 1. Multirooted teeth were assessed considering the worst-scored root. The Decayed, Missing and Filled Teeth (DMFT) Index was calculated.

\section{Statistical Analysis}

All data were analyzed using SPSS for Windows, version 14.0 (SPSS, Chicago, Ill., USA). Pearson's $\chi^{2}$ test for independence was used to analyze the data and a $p$ value of $<0.05$ was considered significant. 
Table 2. Distribution of decayed, missing and filled teeth and PAI scores according to tooth type

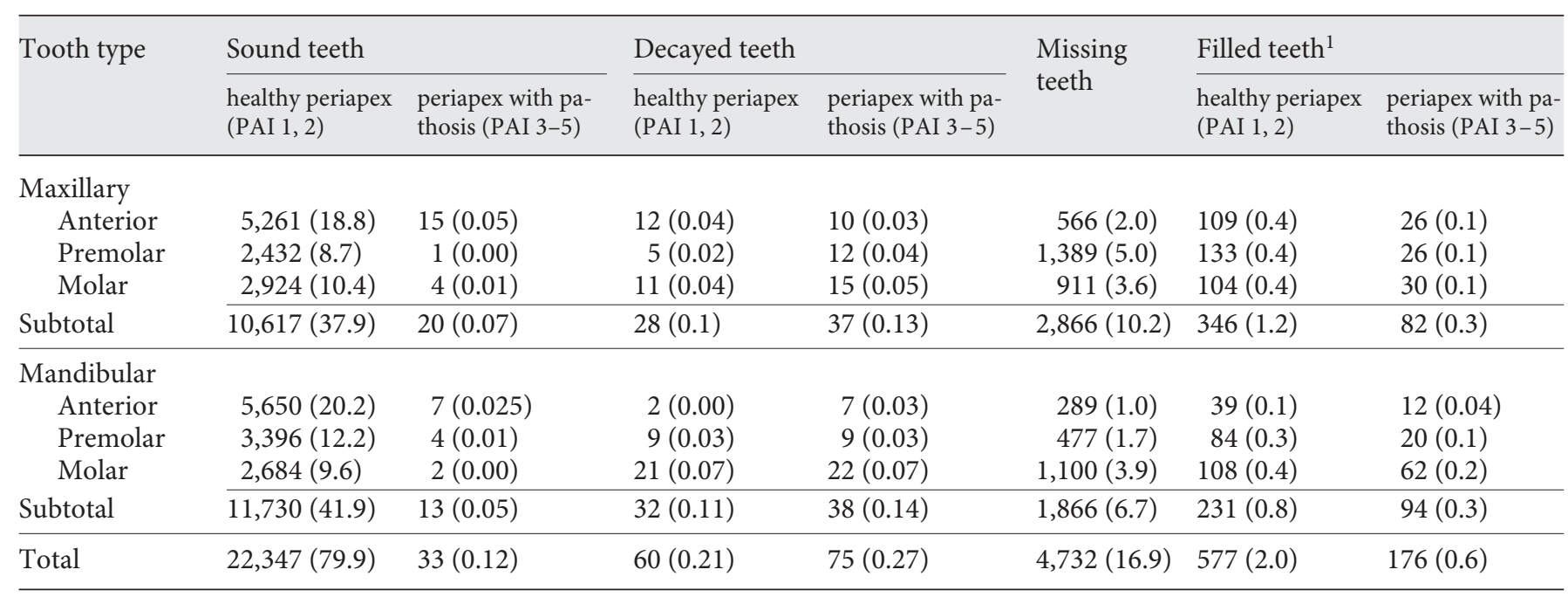

Values represent numbers with percentages in parentheses.

${ }^{1}$ All coronal restorations.

Table 3. Distribution of RFT and PAI scores according to tooth type

\begin{tabular}{|c|c|c|c|c|c|c|}
\hline Tooth type & $\begin{array}{l}\text { Distribution } \\
\text { of teeth }\end{array}$ & $\begin{array}{l}\text { Healthy periapex } \\
(\text { PAI } 1,2)\end{array}$ & $\begin{array}{l}\text { Teeth with AP } \\
\text { (PAI 3-5) }\end{array}$ & $\begin{array}{l}\text { RFT } \\
\text { (overall) }\end{array}$ & $\begin{array}{l}\text { RFT with healthy } \\
\text { periapex (PAI 1,2) }\end{array}$ & $\begin{array}{l}\text { RFT with AP } \\
\text { (PAI 3-5) }\end{array}$ \\
\hline \multicolumn{7}{|l|}{ Maxillary } \\
\hline Premolar & $2,611(11.2)$ & $2,572(11.1)$ & $39(0.2)$ & $142(0.6)$ & $127(0.6)$ & $15(0.06)$ \\
\hline Molar & $3,089(13.3)$ & $3,039(13.1)$ & $50(0.2)$ & $108(0.5)$ & $93(0.4)$ & $15(0.06)$ \\
\hline Anterior & $5,711(24.5)$ & $5,685(24.4)$ & $26(0.1)$ & $35(0.2)$ & $29(0.1)$ & $6(0.03)$ \\
\hline Premolar & $3,523(15.1)$ & $3,490(15.0)$ & $33(0.1)$ & $88(0.4)$ & $76(0.3)$ & $12(0.06)$ \\
\hline Molar & $2,900(12.5)$ & $2,814(12.1)$ & $86(0.4)$ & $123(0.5)$ & $88(0.4)$ & $35(0.15)$ \\
\hline Subtotal & $12,134(52.1)$ & $11,989(51.5)$ & $145(0.6)$ & $246(1.1)$ & $193(0.8)$ & $53(0.2)$ \\
\hline Total & $23,268(100.0)$ & $22,981(98.8)$ & $287(1.2)$ & $601(2.6)$ & $506(2.2)$ & $95(0.4)$ \\
\hline
\end{tabular}

Values represent numbers with percentages in parentheses.

\section{Results}

Of the 28,000 teeth evaluated, $22,380(80.0 \%)$ were sound, 4,732 (16.9\%) missing, 753 (2.6\%) filled and 135 (0.5\%) decayed. The DMFT was 5.62 for this selected population.

Mandibular first molars $(\mathrm{n}=717)$ were the most frequently missing teeth. The distribution of decayed, miss- ing and filled teeth and PAI scores according to tooth type is shown in table 2.

The distribution of the assessed teeth according to tooth type is shown in table 3. A total of 22,981 (98.8\%) of the teeth had healthy periapex. Of these, $506(2.2 \%)$ were root filled. Of the 23,268 teeth, 287 (1.23\%) displayed periapical disease with a PAI score of 3,4 or 5 . 
Table 4. Distribution of PAI scores according to treatment type, radiographic coronal status, length and lateral seal quality of root fillings

\begin{tabular}{|c|c|c|c|c|c|c|c|c|c|}
\hline \multirow[t]{3}{*}{ Type of treatment } & \multicolumn{7}{|c|}{ PAI scores } & \multirow[t]{3}{*}{ Total } & \multirow{3}{*}{$\begin{array}{l}\text { Overall } \\
\text { frequency } \\
\%\end{array}$} \\
\hline & \multicolumn{3}{|c|}{ healthy periapex } & \multicolumn{4}{|c|}{ periapex with pathosis } & & \\
\hline & 1 & 2 & subtotal & 3 & 4 & 5 & subtotal & & \\
\hline Missing coronal restoration & 33 & 9 & $42(76.3)$ & 9 & 4 & 0 & $13(23.7)$ & $55(100.0)$ & 0.2 \\
\hline Amalgam restoration & 0 & 21 & $21(38.9)$ & 25 & 7 & 1 & $33(61.1)$ & $54(100.0)$ & 0.2 \\
\hline Composite restoration & 0 & 13 & $13(50)$ & 8 & 4 & 1 & $13(50)$ & $26(100.0)$ & 0.1 \\
\hline Root canal treatment + amalgam restoration & 158 & 27 & $185(85.3)$ & 27 & 3 & 2 & $32(14.7)$ & $217(100.0)$ & 0.9 \\
\hline Root canal treatment + composite restoration & 83 & 12 & $95(87.2)$ & 12 & 1 & 1 & $14(12.8)$ & $109(100.0)$ & 0.5 \\
\hline Root canal treatment + crown restoration & 163 & 21 & $184(83.6)$ & 29 & 3 & 4 & $36(16.4)$ & $220(100.0)$ & 0.9 \\
\hline \multicolumn{10}{|l|}{ Radiographic coronal status $(\mathrm{n}=753)$} \\
\hline Score 1 & 263 & 67 & $330(82.5)$ & 54 & 11 & 5 & $70(17.5)$ & $400(100.0)$ & $1.7^{\mathrm{a}}$ \\
\hline Score 2 & 117 & 58 & $175(72.6)$ & 48 & 14 & 4 & $66(27.4)$ & $241(100.0)$ & $1.0^{\mathrm{a}}$ \\
\hline Score 3 & 27 & 4 & $31(81.6)$ & 5 & 1 & 1 & $7(18.4)$ & $38(100.0)$ & $0.1^{\mathrm{a}}$ \\
\hline \multicolumn{10}{|l|}{ Lateral seal of root filling $(n=601)$} \\
\hline Score 1 & 226 & 28 & $254(90.1)$ & 22 & 1 & 5 & $28(9.9)$ & $282(100.0)$ & $1.2^{\mathrm{a}}$ \\
\hline Score 2 & 66 & 14 & $80(87.9)$ & 10 & 0 & 1 & $11(12.1)$ & $91(100.0)$ & $15.1^{\mathrm{a}}$ \\
\hline Score 3 & 15 & 1 & $16(84.2)$ & 1 & 2 & 0 & $3(15.8)$ & $19(100.0)$ & $0.1^{\mathrm{a}}$ \\
\hline Score 4 & 130 & 26 & $156(74.6)$ & 44 & 8 & 1 & $53(25.4)$ & $209(100.0)$ & $0.9^{\mathrm{a}}$ \\
\hline
\end{tabular}

Values represent numbers with percentages in parentheses, unless otherwise indicated. ${ }^{a} \mathrm{n}=22,380$.

A total of 753 teeth were treated with one of the treatment types listed in table 4 . Root canal treatment with crown restoration $(220,29.2 \%)$ was the most common type of treatment; $24(3.2 \%)$ teeth were restored with post/core restoration. A significant correlation was found between the types of treatment and the PAI score (Pearson's $\left.\chi^{2}=290.340, p=0.000\right)$. Periapical status was scored as PAI 1 in most of the root canal-treated teeth restored with amalgam or crowns. Most of the periapically diseased teeth (PAI of 3, 4 or 5), with or without root canal treatment, had crown restorations (table 4).

Of the 753 coronal restorations (except post restorations), 400 (53.1\%) were radiographically intact without signs of leakage (acceptable; table 4), whereas 112 (14.9\%) had recurrent decays (unacceptable). There was a significant correlation between the radiographic coronal status and the PAI score (Pearson's $\chi^{2}=29.597, \mathrm{p}=0.000$ ). The teeth with radiographically acceptable restorations displayed healthy periapical regions (PAI scores of 1 and 2; table 4).

Periapical Status of a Turkish Subpopulation
The number of root-filled teeth (RFT) was 601 (2.6\%), mostly in mandibular left first molars (7.5\%); 95 RFT $(0.4 \%)$ displayed periapical disease, with a PAI score of 3,4 or $5 ; 321$ teeth $(53.4 \%)$ had acceptable root filling lengths (root filling terminating 0 to $\leq 2 \mathrm{~mm}$ from the radiographic apex), and $280(46.6 \%)$ root fillings were assessed as unacceptable, considering the length (table 4). A significant correlation was determined between the length of the root fillings and the PAI score (Pearson's $\left.\chi^{2}=32.181, \mathrm{p}=0.000\right)$. Periapical status of teeth with root fillings terminating $>2 \mathrm{~mm}$ from the radiographic apex was determined as diseased (PAI of 3, 4 or 5 ); this parameter was considered more important than extension of root fillings beyond the radiographic apex (table 4).

Of the root canal fillings, 282 (46.9\%) were adequate, both in the coronal and apical halves, whereas 209 (34.8\%) were inadequate, both coronally and apically (table 4). There was a significant correlation between the lateral seal of root fillings and the PAI score (Pearson's $\chi^{2}=$ 
$45.103, p=0.000)$. The periapical status of the teeth with coronally and apically inadequate root fillings was mostly determined as periapically diseased (PAI of 3, 4 or 5; table 4). Both the length and the lateral seal were found to be acceptable in 247 teeth (41.1\%), and only $9.31 \%$ of these had periapical disease. This was significantly less than the RFT with poor quality (Pearson's $\chi^{2}=31.819$, $\mathrm{p}=0.000)$.

\section{Discussion}

When dental caries experience was categorized into four groups based on the DMFT score [15], the DMFT (5.6) of this population belongs to the fourth 'severe' category. High DMFT seemed to be related to the higher missing teeth number than that of the decayed and filled ones. The AP prevalence (1.2\%) of this selected population was lower than that of the selected populations of the other studies from different countries $[3,5-10,16]$. The frequency of RFT in this study was $2.5 \%$, and within $2.0-18.9 \%$ in the other studies $[3,5-10,16]$. However, the frequency of AP in RFT was lower (15.8\%) than that in the previous studies $(18.2-67.9 \%)[3,5-10,16]$. This low AP prevalence could be due to the frequent extraction of teeth with periapical disease and even with pulpitis due to the small number of specialists in endodontics in this region of Turkey. Thus, it is difficult to interpret such epidemiological studies because the number and reasons for the extractions are usually not reported.

In the present study, similar to previous reports, the most frequently missing teeth were mandibular first molars $[17,18]$. This selected population exhibited the highest AP frequency in mandibular molars. At the same time, the most frequent RFT were the mandibular molars. Molars are the first erupted, most commonly threatened and most commonly treated teeth. Moreover, they have the most complex root canal anatomy [9]. Molars are reported to have higher AP frequency than anterior teeth in various studies $[5,8]$.

The technical quality of the coronal restoration and endodontic treatment should have a seal of good quality to prevent periapical disease $[3,19-21]$. Despite the limitations of radiographic evaluation of coronal leakage, our results obtained from this selected population support the necessity of good seal whether in coronal or apical segments, consistent with other studies $[3,6]$. The $51.1 \%$ frequency of radiographically acceptable coronal restorations of this study was lower than the previously reported
$73.5-75 \%[2,16]$. Regarding the type of coronal restoration, the present study demonstrated that the most decisive risk factor for developing AP was the presence of crowns, which is in agreement with other studies $[5,19]$. Apart from the inadequate marginal adaptation or recurrent decay, various iatrogenic factors during the prosthetic procedures, such as excessive preparation and mechanical, thermal, chemical and occlusal trauma, can explain this outcome.

In this study, the quality of the root fillings has been evaluated in terms of length and homogeneity of root fillings adopting the criteria from Hommez et al. [6] and Kirkevang et al. [3]. The apical limit of obturation of the root canal has been a topic for discussion among endodontists for decades, but there is an agreement in the literature that the length of the root filling is a crucial factor for the success of endodontic treatment $[6,7,16]$. In clinical practice, the limits of instrumentation and obturation are accepted to be between 0.5 and $2 \mathrm{~mm}$ from the radiographic apex, even though the position of the apical foramen has been found to be between 0.2 and $3.8 \mathrm{~mm}$ from the radiographic apex [20].

Teeth with adequate lengths of root fillings had 10.9\% AP in this selected population, whereas other European populations had $10-46 \%[22,23]$. Teeth with short root fillings had 49-90.8\% AP [7, 9] and long ones had 55-75\% $[7,12,22]$. In the present study, the frequency of short treatments $(40.3 \%)$ was significantly higher than long ones $(6.3 \%)$, which led to significantly more AP $(21.9 \%)$. According to our clinical experience and the findings of other studies, overfilling usually results in endodontic infections due to overinstrumentation, through infected dentin chips being propelled into the periradicular tissues or due to lack of an apical seal leading to apical percolation [7]. In contrast, in short fillings, a root canal may not have been cleaned in the apical segment and not sealed appropriately, leaving enough space for growth of residual microorganisms.

There is still some disagreement about the effects of the homogeneity of the root filling on the periapical status $[3,6,23]$. Radiographic evaluation methods usually do not allow determining the true relation between the root dentine and filling material. First and foremost, three-dimensional evaluation is not possible with radiographs. The present study reported that $53.1 \%$ of the root fillings had detectable adaptation failures and, of these, 53.21\% had AP. Similar results have been reported in previous studies having root fillings with voids of between 30 and $60 \%$, and, approximately $58-70 \%$ of these had AP $[3,12,22]$. The incomplete diagnostic val- 
ue of radiographs still remains a limitation of the present and other studies. However, further studies utilizing more sensitive techniques, such as cone beam computed tomography, have the potential to assess the true periapical status.

\section{Conclusions}

The data from this selected population recorded the highest AP frequency in mandibular molars. Tooth type had a significant impact on the periapical status. The radiographic quality and type of coronal restorations also had a significant impact on the periapical status, as did the length and homogeneity of the root fillings.

\section{References}

$\checkmark 1$ Fleming $\mathrm{CH}$, Litaker MS, Alley LW, et al: Comparison of classic endodontic techniques versus contemporary techniques on endodontic treatment success. J Endod 2010;36: 414-418.

- Sjogren U, Hagglund B, Sundqvist G, et al: Factors affecting the long-term results of endodontic treatment. J Endod 1990;16:498-504.

-3 Kirkevang LL, Ørstavik D, Hörsted-Bindslev $\mathrm{P}$, et al: Periapical status and quality of root fillings and coronal restorations in a Danish population. Int Endod J 2000;33:509-515.

-4 Huumonen S, Ørstavik D: Radiological aspects of apical periodontitis. Endod Topics 2002;1:3-25.

$\checkmark 5$ Loftus JJ, Keating AP, McCartan BE: Periapical status and quality of endodontic treatment in an adult Irish population. Int Endod J 2005; $3: 81-86$.

6 Hommez GM, Coppens CR, De Moor RJ: Periapical health related to the quality of coronal restorations and root fillings. Int Endod J 2002;35:680-689.

7 Siqueira JF Jr, Rôças IN, Alves FR, et al: Periradicular status related to the quality of coronal restorations and root canal fillings in a Brazilian population. Oral Surg Oral Med Oral Pathol Oral Radiol Endod 2005;100: 369-374.

8 Georgopoulou MK, Spanaki-Voreadi AP, Pantazis N, et al: Frequency and distribution of root filled teeth and apical periodontitis in a Greek population. Int Endod J 2005;38:105111.
-9 Sunay H, Tanalp J, Dikbas I, et al: Cross-sectional evaluation of the periapical status and quality of root canal treatment in a selected population of urban Turkish adults. Int Endod J 2007;40:139-145.

10 Gulsahi K, Gulsahi A, Ungor M, et al: Frequency of root-filled teeth and prevalence of apical periodontitis in an adult Turkish population. Int Endod J 2008;41:78-85.

11 Ørstavik D, Kerekes K, Eriksen HM: The periapical index: a scoring system for radiographic assessment of apical periodontitis. Endod Dent Traumatol 1986;2:20-34.

12 Eriksen HM, Ørstavik D, Kerekes K: Healing of apical periodontitis after endodontic treatment using three different root canal sealers. Endod Dent Traumatol 1988;4:114-117.

13 Delano EO, Ludlow JB, Ørstavik D, et al: Comparison between PAI and quantitative digital radiographic assessment of apical healing after endodontic treatment. Oral Surg Oral Med Oral Pathol Oral Radiol Endod 2001;92:108-115.

14 Cohen J: A coefficient of agreement for nominal scales. Educ Psychol Meas 1960;20:3746.

15 Hallett KB, O’Rourke PK: Dental caries experience of preschool children from the north Brisbane region. Aust Dent J 2002;47:331338.

16 De Moor R, Hommez G: The importance of apical and coronal leakage in the success or failure of endodontic treatment. Rev Belge Med Dent 2000;55:334-344.
17 Shigli K, Hebbal M, Angadi GS: Relative contribution of caries and periodontal disease in adult tooth loss among patients reporting to the Institute of Dental Sciences, Belgaum, India. Gerodontology 2009;26:214-218.

18 Chrysanthakopoulos NA: Reasons for extraction of permanent teeth in Greece: a five-year follow-up study. Int Dent J 2011;61:19-24.

19 Buckley M, Spangberg LS: The prevalence and technical quality of endodontic treatment in an American subpopulation. Oral Surg Oral Med Oral Pathol Oral Radiol Endod 1995;79: 92-100.

20 Ricucci D, Grondahl K, Bergenholtz G: Periapical status of root-filled teeth exposed to the oral environment by loss of restoration or caries. Oral Surg Oral Med Oral Pathol Oral Radiol Endod 2000;90:354-359.

21 Kalender A, Orhan K, Aksoy U, et al: Influence of the quality of endodontic treatment and coronal restorations on the prevalence of apical periodontitis in a Turkish Cypriot population. Med Princ Pract, E-pub ahead of print.

22 Eriksen HM, Bjertness E: Prevalence of apical periodontitis and results of endodontic treatment in middle-aged adults in Norway. Endod Dent Traumatol 1991;7:1-4.

23 Eriksen HM, Berset GP, Hansen BF, et al: Changes in endodontic status 1973-1993 among 35-year-olds in Oslo, Norway. Int Endod J 1995;28:129-132. 